\title{
Fabrication and Characteristic of Green-Concrete by Using Recycled Steel Slag
}

\author{
Lianxia Ma ${ }^{1}$, Zhengxun Yang ${ }^{1,{ }^{*}}$, Wei Chen ${ }^{1}$, Fang Chen ${ }^{1}$, \\ and Xiaoling Zhong ${ }^{1}$ \\ ${ }^{1}$ Xinjiang Communication Construction Group, China \\ 16709263@qq.com
}

\begin{abstract}
Key words: Steel slag, compressive strength, $\mathrm{CO}_{2}$ emission, green concrete
Abstract:To replace steel slag for natural sand completely, the mix proportions of steel slag in concrete was adjusted according to tab density and replacement ratio of Metakaoline/Cement were established. And then testing for slump, setting time, and compressive strength was conducted. According to test results, the compressive strength of concrete using steel slag was lower than that of concrete using natural sand (BAO concrete). But by adjusting the amount of steel slag in concrete according tab density so that the fine aggregate proportions change $44 \%$ to $38 \%$, the compressive strength of concrete using the steel slag could even be higher than BAO concrete. And the chloric content of concrete using steel slag increased as the replacement ratio of steel slag increased, but it is satisfied with the chloric content of fresh concrete $0.30 \mathrm{~kg} / \mathrm{m}^{2}$ below(concrete standard specification regulation value).
\end{abstract}

\section{Introduction}

Nowadays, more researches are focused on environment-friendly construction materials. To reduce $\mathrm{CO}_{2}$ emission, steel slag concrete is expected to replace the natural aggregate based cement concrete. ${ }^{[1]}$ Recently the steel slag production has been increased by increase of consumption of steel and iron. So it is important to secure a reclaimed land and treatment utility for steel and iron slag. ${ }^{[2]}$

The slag produced by steel factory is classified into steel slag and iron slag, according to the raw minerals and equipments. The ratio of recycled steel slag is only 10 15\% and mostly land filled so that recycling would be an important topic discussed year by year. Moreover, recent natural aggregate supply was limited and river sand has been banned both on using and exploring, so an alternative should be found to solve the shortage of raw material. ${ }^{[3]}$ The physical and chemical properties of steel slag meet the requirement for replacing fine aggregate in concrete production.

So in this experiment to compare and analyze the properties of concrete by replacement natural sand to steel slag, the mix proportions of concrete $\mathrm{W} / \mathrm{C}(40,50,60 \%)$ and replacement ratio of steel $\operatorname{slag}(0,10,20,35,50 \%)$ were established, and then tested for slump, and compressive strength.

\section{Experimental procedures}

The ordinary Portland cement, coarse crushed gravel near the mountain, river sand, and metakaolin were used as raw materials. Mixing of concrete was done in mixer with capacity of 100L. Aggregate, cement, and steel slag were first dry mixed for $3 \mathrm{~min}$ then wet mixed for another $5 \mathrm{~min}$ with water addition. After mixing, the concrete mortar was poured into moulds for compressive strength test. The specimens were cured in air for $24 \mathrm{hr}$ and in water for 7 -days and 28 days. Then the compressive strength was measured respectively. The amount of cement, steel slag and mekakaolin were varied for application investigation.

The fly ash and metakaolin were added to enhance the strength of steel slag concrete at amount of $0 \sim 10$ and $0 \sim 15$ respectively. And the cement/steel slag ratio, steel slag/aggregate ratio were also varied to get a optimal compressive strength value for practical applications. The particle size 
distribution of steel slag and natural sand were measure by sieving test. The microstructure of each specimen was investigated by a scanning electron microscope.

\section{Results and discussion}

Particle size distribution curve of the steel slag was shown in Fig. 1 with the upper and lower limit of particle size distribution of natural sand. The amount of fine particles in steel slag that are less than $0.3 \mathrm{~mm}$ is so large that as shown in Fig.2a), the strength of steel slag concrete reduced drastically mainly due to large amount of fine particles than sand.

Highest strength was reached when adding 5\% fly ash as shown in Fig. 2b). The pozzolana and hydraulic activity of fly ash have mainly been pointed out as well as the possibility to use this addition as a concrete component. ${ }^{[4]}$ The fly ash addition, in considered range of FA/C values, has no significant effect on specific gravity and water absorbability of concrete but the addition reduces the capillary suction of water. However, too much amount could cause the water consumption increase that reduce the strength.

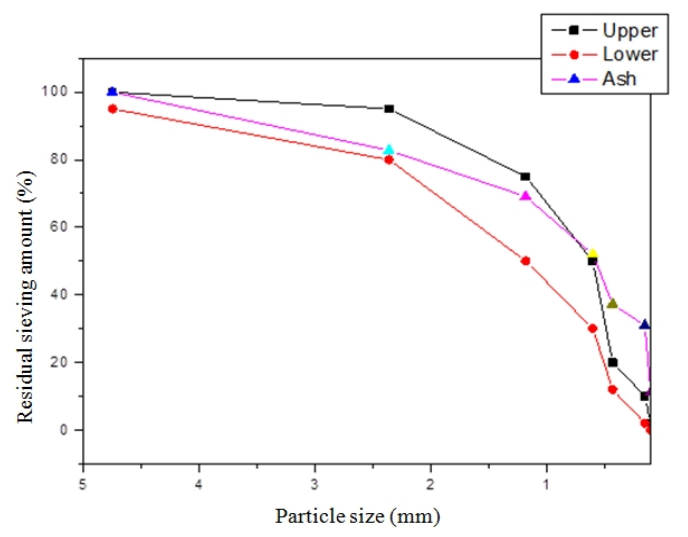

Fig.1. The particle size distribution curves of the steel slag.
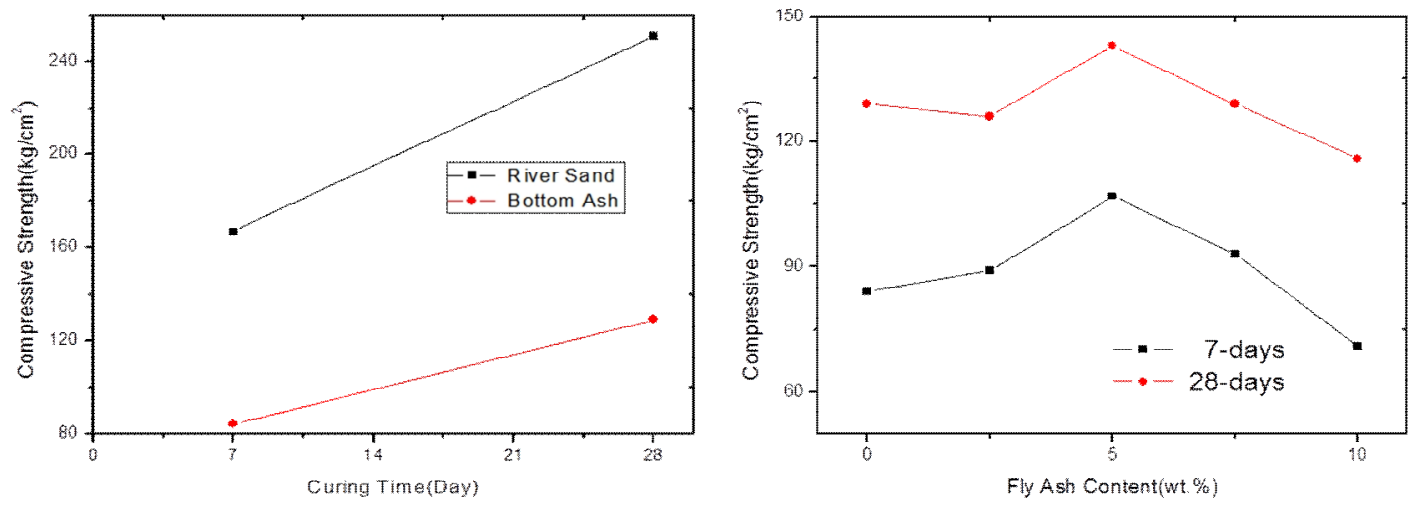

Fig.2. The compressive strength of steel slag used concrete and the effect of fine particles in Steel slag.

As an ordinary strength increasing method of the concrete, the amount of Portland cement was increased. But as shown in Fig.3a), the strength also decreased as the amount of cement increases due to the low $\mathrm{W} / \mathrm{C}$ ratio. So the ratio of cement to steel slag is varied with certain amount of steel slag of $30 \%$ (total amount) and 30\% (matrix part) of cement/steel slag ratio was found to be the optimal value for the highest strength. In this case the strength increased for the cement amount increase and decreased for the low W/C ratio, which could be seen as Fig.3b). 


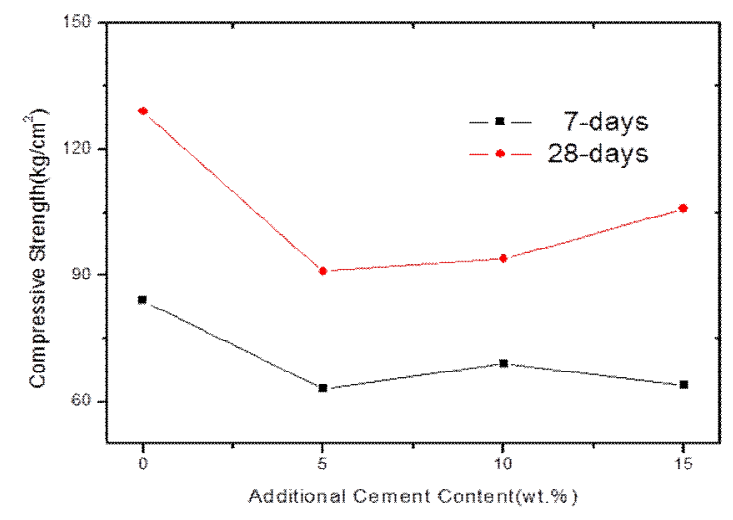

a)

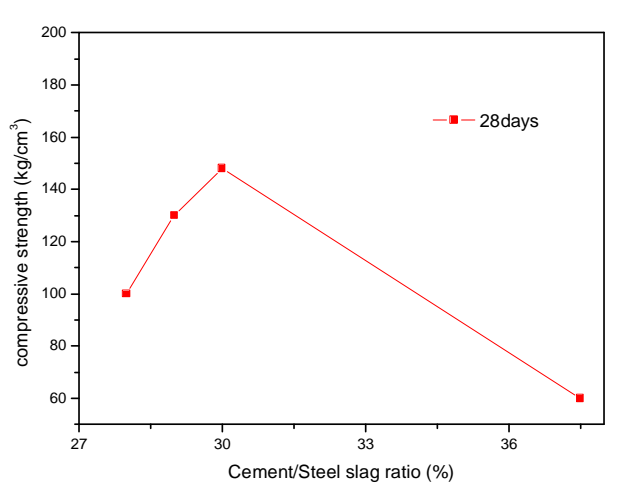

b)

Fig.3. The compressive strength of steel slag used concrete with the amount of Portland cement.

Fig.4 a) shows the compressive strength varied with ratio of steel slag to aggregate. For the amount of fine powder existed in steel slag was large and it would consume more water, lower amount of steel slag performed higher strength for the reduction of water. The strength drastically increased when the ratio is below $72 \%$. And the strength around $200 \mathrm{kgf} / \mathrm{cm}^{3}$ is capable for road construction application. As a conventional additive for construction material, the metakaolin doesn't make good effort for strength. Low amount of metakaolin addition even caused strength reduction.

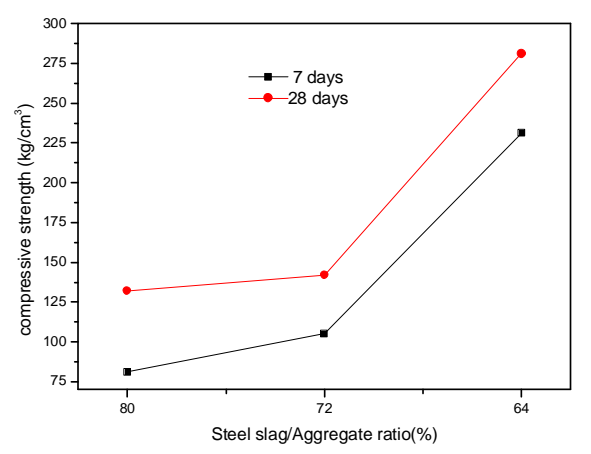

a)

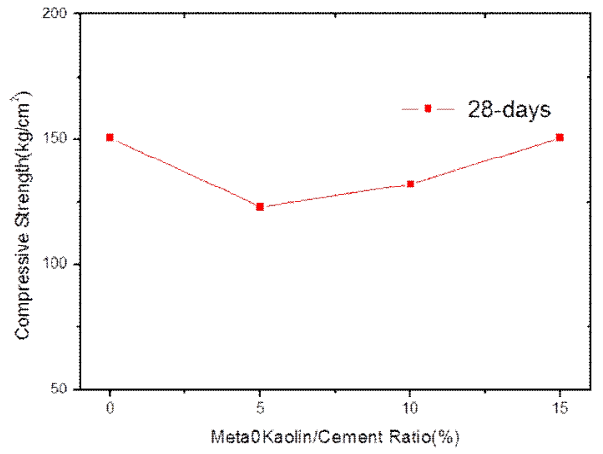

b)

Fig.4. The compressive strength of steel slag used concrete with the amount of a) Portland cement and b) metakaoline as an admixtures.

The microstructure comparison of steel slag based concrete with fly ash and metakaolin addition is shown in Fig.5. The introduction of fly ash smoothes the matrix structure for its self-cementing feature (Fig.5b). When finer fly ash particles partially replace Portland cement, the heterogeneities in microstructures of hydrated Portland cement paste are reduced greatly. Further, when the pozzolanic reaction proceeds, there is a gradual decrease in both the size of capillary pores and crystalline hydration products, thus eliminating the weak link in the concrete microstructure. Thus the product is highly crack resistant and durable. Although the addition of metakaolin also reduced the pore amount and size compared to the sample without additive, the structure still seemed loose especially at matrix and aggregate bonding parts (Fig.5c)). 


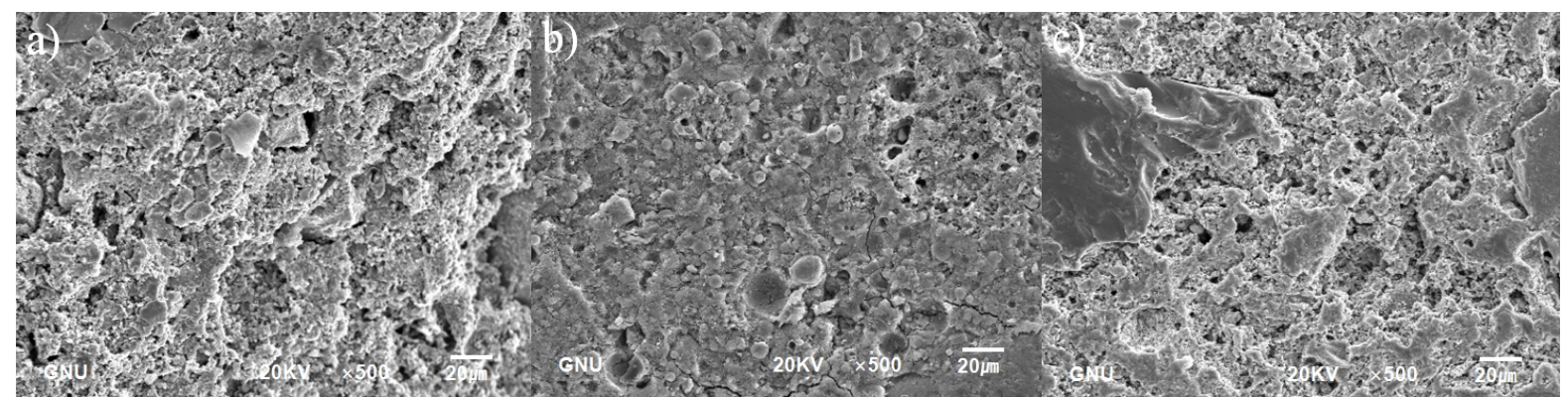

Fig.5 SEM microstructures of a) steel slag only, b) with 5\% fly ahs addition, and c) with 5\% metakaolin addition

\section{Conclusion}

The replacement of steel slag for natural sand is researched to improve the engineering properties of concrete. The following results were reviewed.

1) The rate of addition of extra cement doesn't give contribution for strength enhancement for the lower W/C ratio. And 30\% is found to be the optimal ratio for cement/steel slag ratio.

2) If the steel slag to aggregate ratio decreased from $80 \%$ to $64 \%$, the strength of concrete can reach to $250 \mathrm{~kg} / \mathrm{cm}^{3}$, which is capable for road construction application.

3) Proper amount of fly ash addition is helpful for strength increasing, for its pozzolanic and hydraulic activity. Too much amount $(>5 \%)$ would cause a reduction of strength because the fine particle of fly ash consumes water a lot.

\section{Acknowledgement}

This work was financially supported by China Postdoctoral Science Foundation.

\section{References}

[1] L. B. Andrade, J. C. Rocha and M. Cheriaf, "Aspects of Moisture Kinetics of Coal Fly ash in Concrete", Cement and Concrete Research, Volume 37, Issue 2, February 2007, Pages 231-241

[2] L. B. Andrade, J. C. Rocha and M. Cheriaf, "Evaluation of Concrete Incorporating Fly ash as a Natural Aggregates Replacement", Waste Management, Volume 27, Issue 9, 2007, Pages 11901199

[3] Apha Sathonsaowaphak, Prinya Chindaprasirt and Kedsarin Pimraksa, "Workability and Strength of Lignite Fly ash Geopolymer Mortar", Journal of Hazardous Materials, Volume 168, Issue 1, 30 August 2009, Pages 44-50

[4] Haldun Lurama and Mine Kaya, "Usage of Coal Combustion Fly ash in Concrete Mixture", Construction and Building Materials, Volume 22, Issue 9, September 2008, Pages 1922-1928 